\title{
BMJ Global Health Supportive supervision to improve service delivery in low-income countries: is there a conceptual problem or a strategy problem?
}

\author{
Gertrude Sika Avortri, ${ }^{1}$ Joy Belinda Nabukalu, ${ }^{2}$ Juliet Nabyonga-Orem ${ }^{1}$
}

\begin{abstract}
To cite: Avortri GS, Nabukalu JB Nabyonga-Orem J. Supportive supervision to improve service delivery in low-income countries: is there a conceptual problem or a strategy problem?BMJ Glob Health 2019:4:e001151. doi:10.1136/ bmjgh-2018-001151
\end{abstract}

Handling editor Seye Abimbola

Received 1 September 2018 Revised 7 November 2018 Accepted 23 November 2018

Check for updates

C Author(s) (or their employer(s)) 2018. Re-use permitted under CC BY-NC. No commercial re-use. See rights and permissions. Published by BMJ.

${ }^{1}$ Health Systems and Services Cluster, World Health Organization, Inter-Country Support Team for Eastern and Southern Africa, Harare, Zimbabwe

${ }^{2}$ Independent Consultant, HealthNet Consult, Kampala, Uganda

Correspondence to Dr Juliet Nabyonga-Orem; nabyongaj@who.int

\section{ABSTRACT}

Supportive supervision is perceived as an intervention that strengthens the health system, enables health workers to offer quality services and improve performance. Unfortunately, numerous studies show that supervisory mechanisms in many low-income countries (LICs) are suboptimal. Further, the understanding of the concept and its implementation is still shrouded in misinterpretations and inconsistencies. This analysis contributes to a deeper understanding of the concept of supportive supervision and how reorganisation of the approach can contribute to improved performance. The effectiveness of supportive supervision is mixed, with some studies noting that evidence on its role, especially in LICs is inconclusive. Quality of care is a core component of universal health coverage which, accentuates the need for supportive supervision. In the context of LICs, it is imperative for supportive supervision to be implemented as an on-going approach. Factors that affect supportive supervision encompass cultural, social, organizational and context dimensions but the capacity of majority of LIC to address these is limited. To this end, we underscore the need to review the supportive supervision approach to improve its effectiveness, and ensure that facility-based supervision embodies as many of the envisioned qualities as possible. We thus make a case for a stronger focus on internal supportive supervision where internal refers to health facility/unit/ward level. Inherent in the approach is what we refer to as 'supervisee initiated supportive supervision'. The success of this approach must be anchored on a strong system for monitoring, data and information management at the health facility level.

\section{BACKGROUND}

Supportive supervision is perceived as an intervention that strengthens the health system, enables health workers to offer quality services and improves performance. ${ }^{1}$ In low-income countries (LICs), the primary healthcare (PHC) movement highlighted the need for supportive supervision to link remote workers to the health system and supplement their training. ${ }^{2}$ The concept of supervision has evolved over the decades,
Summary box

- Supportive supervision has the potential to improve the quality of health care and management, enhance skills of health workers and improve performance.

- Supervisory mechanisms in many low-income countries have low coverage, are irregular, unsupportive and demotivating.

- Evidence on realising and sustaining envisaged benefits from supportive supervision is mixed.

- To realise the full benefits that the intervention accords, limited understanding on what constitutes effective supportive supervision, and how different supervision approaches influence performance in different social and cultural contexts need to be addressed.

- A methodological shift that builds capacity at the lower levels of service delivery for internal supportive supervision especially in health facilities will reduce the systemic and logistical implementation challenges.

influenced largely by supervisory practices from the political, business and industrial arena. ${ }^{3}$ It encompasses various ideas, different approaches and methods from different disciplines. ${ }^{4}$ Are the variations explained by lack of conceptual clarity? Martin et al raise this concern highlighting the lack of consensus on the definition as well as the most effective models, processes and methods. ${ }^{5}$ Definitions aside, what supportive supervision entails is another murky area, while some relate supportive supervision to 'facilitative, clinical or professional supervision ${ }^{6}$ others equate it to 'mentoring' and 'quality improvement" and indeed use these terms interchangeably.

The low numbers, inadequate skills and inefficiencies in management of the available health work force in $\mathrm{LIC}^{8}{ }^{8}$ accentuate the need for supportive supervision as one of the interventions to improve performance. ${ }^{9}$ Unfortunately, supervisory mechanisms in 
many LICs have low coverage, are irregular, unsupportive and demotivating. ${ }^{10}$ Scholars emphasise the need for a better understanding of the human interactions involved if efforts to transform the traditional form of supervision that comprised top-down authoritarian approaches, to new methods that are more liberal and collaborative, are to deliver expected improvements. ${ }^{11}$ We also argue that the understanding of the concept and its implementation is still shrouded in misinterpretation and inconsistencies. Healthcare organisation have an obligation to ensure that supportive supervision is defined, appropriate and supported to be effective. In undertaking this analysis, we draw on varied concepts from different disciplines to examine the concept of supportive supervision and implementation approaches in healthcare delivery in LICs. We further explore the different supportive supervision mechanisms, innovative approaches and their impact on performance and quality of services. The objective of this analysis is to contribute to a deeper understanding of the concept of supportive supervision and how reorganisation of the approach can contribute to improved performance in LICs.

\section{CONCEPTUALISATION OF SUPPORTIVE SUPERVISION IN THE HEALTH SECTOR}

Supervision in the health sector dates as far back as the early 1900s when it was conceived as an organisational and management process. ${ }^{12}$ In the initial stages, a traditional form of supervision based on a top-down authoritarian approach was introduced. ${ }^{11}$ Contemporary methods that are more liberal and collaborative are believed to have evolved from USA and the UK. ${ }^{3}$

Supportive supervision has been defined in several ways as "provision of guidance and feedback on matters of personal, professional and educational development ${ }^{13}$; as 'an approach that emphasises mentoring, joint problem solving, two-way communication ${ }^{6}$ and as 'a process that promotes quality at all levels of the health system'. ${ }^{14}$ Garrison et al defines the concept as a process of guiding, helping, training and encouraging staff to improve their performance continuously in order to provide high-quality health services. ${ }^{15}$

Though a number of definitions and models of supervision have been developed, the concept still remains ill-defined. ${ }^{16}$ The word supervision is a coinage from two Latin words: 'super' and 'video'. Super means 'over' or 'above', while video means 'to see'. Taken together, super video means 'to see from above' or to 'oversee'. ${ }^{17}$ Supervision has thus been defined as 'to oversee, to superintend or to guide and to stimulate the activities of others, with a view of their improvement'. ${ }^{3}$ Some scholars denote superiority in the supportive supervision concept as: 'an intervention provided by a senior member to a junior member of the same profession'. ${ }^{18}$ This view of supervision seems to have greatly influenced the design of the traditional supervisory approaches which were characterised with issuing of orders, intimidation with a focus on data collection and use of checklists.

Over the years, the traditional supervision model has been realised to be unproductive, necessitating a shift to a more facilitative approach that promotes mentorship, joint problem-solving and communication between supervisors and supervisees. ${ }^{11}$ Supportive supervision encounters should typically include performance observation and comparison of actual practices with standards; facilitative feedback on performance; provision of guidelines or technical updates; ascertaining opportunities for improvement; problem solving as a team and follow-up of previously noted problems. ${ }^{14}$ Scholars draw our attention to the importance of human interactions highlighting the importance of a relationship between supervisor and supervisee in which the responsibility and accountability for the development of competence, demeanour and ethical practice take place. ${ }^{19}$ In this context, the supervisor is responsible for providing direction to the supervisee, who applies relevant work theory, standardised knowledge, competency and applicable ethical content in the practice setting in a collaborative process.

Attempts have been made to distinguish clinical, professional and managerial or line supervision. ${ }^{20}$ Managerial supervision is carried out by a supervisor with authority and accountability for the supervisee. Clinical and professional supervision on the other hand are often used interchangeably to refer to an approach where staff are given the opportunity to reflect on and review their practice, discuss individual cases in depth, change or modify their practice and identify training and continuing development needs. ${ }^{19}$ Other scholars state that supportive supervision covers three main overlapping domainsadministrative, educational and supportive. ${ }^{21}$ While the administrative component addresses issues of meeting policy and guidelines requirements, the educational aspect deals with learning relationships between supervisor and supervisee and monitoring clinical and professional developments of supervisees, and the supportive element relates to decreasing supervisees job stress, motivation and creating a work environment that facilitates performance. Schriver et al, however, caution that attempts to distinguish between managerial, education and supportive supervision may represent a simplification of interrelated aspects as the components overlap. ${ }^{22}$ Likewise, while some definitions differentiate supportive supervision from mentoring and coaching, ${ }^{23}$ others emphasise mentoring, team work, joint problem solving and open communication as major dimensions of supportive supervision. ${ }^{14}$

Other types of supportive supervision employed in LICs include individual supportive supervision which aims to improve clinical or managerial performance and respond to professional development needs of an individual. Integrated supportive supervision which focuses on supporting the service delivery team to provide responsive and quality services, build capacity for self-assessment and joint problem solving, comply with standards 
and build teamwork. Integrated supportive supervision of management systems focuses on improving management functions through ensuring proper implementation of government policy and guidelines, adherence to standards and improving coordination of health actors. Emergency supportive supervision on the other hand seeks to support response efforts to emergencies. ${ }^{24-27}$

\section{EFFECT OF SUPPORTIVE SUPERVISION}

Evidence on the effectiveness of supportive supervision is mixed with some studies reporting that its role, especially in LICs, is inconclusive. ${ }^{28}$ Some studies have linked supportive supervision to positive outcomes such as job motivation, retention, satisfaction and better performance. ${ }^{29}$ Supervisory dimensions of task assistance, social and emotional support and interpersonal interaction have been highlighted as beneficial outcomes for health workers. ${ }^{30}$ Additionally, evidence shows that improving supervision quality has a greater impact than increasing frequency of supervision alone. ${ }^{2}$

Improved adherence to clinical guidelines has been reported. In Ethiopia, for example, the consistency in pneumonia case management improved from $38 \%$ to $78 \%$ during the first to the fourth supportive supervision. ${ }^{31}$ Improved adherence to standards and guidelines for emergency obstetric care was reported in Uganda. ${ }^{32}$ Other studies observed supportive supervision related improvements in medicines management, ${ }^{33}$ treatment of common childhood illnesses ${ }^{34}$ and general quality of health care. ${ }^{35}$

On the contrary, however, some studies demonstrate no positive effects. Madede et al found no statistically significant differences between health workers job satisfaction scores pre-supportive and post-supportive supervision. ${ }^{36}$ Bosch-Capblanch et al in a systematic review to ascertain whether supervision has a positive effect on the quality of PHC in LICs and middle-income countries posit that the long-term effectiveness of supervision is unknown. ${ }^{37}$

\section{FACTORS THAT INFLUENCE SUPPORTIVE SUPERVISION}

Factors that promote effective supervision have been highlighted as: (1) good knowledge of the local situation; (2) opportunity for the supervisor and supervisee to work together on the issue; (3) frequent constructive feedback and (4) structured or scheduled supervision with agreed content and learning objectives. ${ }^{13}$ Furthermore, the level of knowledge and skills of supervisors in teaching, assessment, counselling, appraisal, feedback, career advice and interpersonal relationship are key. ${ }^{13}$

Evidence highlights three main factors that contribute to supervisory outcomes including task assistance (eg, provision of tangible work-related advice, instruction, support training and learning activities such as coaching), social and emotional support (ie, listening to workers as they discuss job difficulties, providing supportive statements and relating to the emotional needs of the workers when they feel overwhelmed, stressed or confused by their work) and quality interpersonal interaction. Task assistance, however, offers the greatest impact on positive worker outcome. ${ }^{1838}$

Regarding organisational context, the policy environment, the value or priority accorded to the supervision function and the existing organisational configurations play an important role in how supervision interventions are implemented. ${ }^{28}$ The organisational objectives for issues such as productivity, flexibility, costs, health and safety greatly influence the design of structures, which includes supportive supervision. ${ }^{39}$ Additionally, the acceptability of supervision need to be understood in a social and cultural context. ${ }^{11}$

\section{SUPPORTIVE SUPERVISION STRUCTURES AND PROCESSES IN LICS}

A favourable policy environment where supportive supervision has clearly defined and accountable structures and is firmly anchored in sector performance management processes is essential. Most LICs have developed supervisory structures or a system for the health sector, and diverse mechanisms and strategies have been employed. Among the strategies is development and application of policy/guidelines and tools, training, continuous supervision and support, monitoring of provider performance and availing required logistics. 3640

An analysis of the supportive supervision in Tanzania and Malawi noted a favourable attitude towards, and more support for supportive supervision, as well as a paradigm shift towards more supportive and problem solving approaches in Tanzania, attributable to the policy environment. ${ }^{28}$ Limitation in supportive supervision polices/guidelines impact on implementation approaches. For example, while countries like South Africa $^{24}$ and Ethiopia ${ }^{25}$ put in place policies and guidelines that adopted a whole systems supportive supervision approach with an emphasis on improving sector performance, other country efforts were disease or programme specific. ${ }^{40}$ Regarding conceptualisation of supportive supervision, different views emerge. Some countries perceive supportive supervision as a process with an intended outcome (improved health outcomes, enhanced skills of health workers) ${ }^{27} 42$ as regular visit to monitor performance ${ }^{25}$ and as a range of measures to ensure that supervisors carry out their work. ${ }^{41}$

In practice, supportive supervision strategies vary greatly in approach, content and tools. In most instances, supportive supervision tends to be the responsibility of external top-level officials. ${ }^{28}{ }^{43}$ Vasan et al observed that the focus on external top-level supervisor could be attributed to the fact that most of these are donor supported with the quest to impose managerial agendas and power dynamics within organisations, and a growing 'risk' of practitioners' well-being often underpin the institutionalisation of external supportive supervision mechanisms. ${ }^{44}$ In other instances, implementation of supervision is sourced externally through private 
arrangements-contracted out to agencies or individual practitioners. ${ }^{44}$ Suffice to say that composition of some of the outsourced teams do not always meet the technical expertise or qualification required.

Generally, supervision paradigms are one of periodic inspection and control, ${ }^{28}$ with so much focus on collecting and analysing data. ${ }^{45}$ Other studies have noted that supportive supervision sessions were used as opportunity to check reports and or avenues to organise meetings on a broad range of general issues. ${ }^{43}$ Bradley et al note that supervisors grapple with several demands in their capacity as managerial supervisors combined with clinical supervisory responsibility either within the health facility in which they were based or to different health facilities. ${ }^{28}$ Usually tools such as checklists, job aids, guidelines and, to some extend, mobile technology or e-Health devices are used to facilitate data collection, identification problems and record-keeping. ${ }^{7}$ Unfortunately, these tools often captured a huge number of indicators leading to difficulties in compiling, interpreting and use of the findings during the visit to support staff. Rarely do focused or technical supportive supervision visits by people with expertise in specific areas take place. Evidence highlights staff frustration with their supervisors due to their inability to respond to their concerns. ${ }^{43}$ In Rwanda, for example, instead of external supervisors helping supervisees' professional development, they rather focused on evaluating their performance against the performance-based financing benefits. $^{22}$

Combined approaches have shown some positive results. George et al document an initiative in Uganda that utilised mentoring with a combination of external specialist teams and local mentors that resulted in more productivity, increased problem identification and solving, improved management of patients and health worker skills. ${ }^{46}$ They, however, noted challenges with documentation practices and use of self-assessment tools. In their view, initial involvement of external mentors, involvement of local leadership and having mentees that are passionate and interested in the initiative were key success factors. PHC supervision initiative in South Africa comprised regular review of PHC facility performance, in-depth programme review, problem-solving discussions and improvement planning, training and review of previous actions taken since the last supervision visit and new actions to follow. ${ }^{47}$ In their assessment of PHC supervision initiative in South Africa, Jacobs et al reported improvements in supportive supervision processes but no demonstrable impact. ${ }^{47}$

Noteworthy is the fact that majority of interventions to improve supportive supervision in LIC are externally funded $^{22} 48$ and are pilot projects. ${ }^{40}{ }^{43}$ Scaling-up and sustenance of improvements even in the pilot sites fizzle out once donor funding is withdrawn. Evidence shows that supportive supervision provision in its current state is insufficient to meaningfully improve the quality of care in countries. ${ }^{49}$
A number of limiting factors characteristic to LIC include low coverage, lack of motivation and inadequate training for supervisors on problem-solving methodologies. ${ }^{37}$ Others relate to inadequate supervisory skills, poor staff attitude, lack of transport, lack of support from the national level and lack/non-use of supervisory tools. ${ }^{50}$ There are instances where supervisors themselves attested to being ineffective and expressed the need to transform their supervisory approaches to be more collaborative, transparent, team building and caring. ${ }^{50}$ An assessment in Pakistan observed that supervisors had varied understanding of the definition of supervision, lacked requisite knowledge and skill. ${ }^{51}$

\section{NEED FOR CHANGE IN STRATEGY}

We underscore the need to review the supervision strategy to improve its effectiveness and ensure that facility-based supervision embodies as many of the envisioned qualities as possible. It is also evident that despite huge investments in supportive supervision interventions, expected improvements have not and may not be achieved without a better understanding of the human interactions involved and a change in strategic direction that directs investments to mitigate the factors that hinder its implementation.

In the context of LICs, it is imperative for supportive supervision to be implemented as a continual, ongoing approach. Contextual, institutional and logistical challenges continue to hinder supportive supervision. In this regard, we make a case for a stronger focus on internal supportive supervision. Internal in this regard refers to health facility/unit/ward level. In this approach, the supervisors are on-site, thus limiting logistical requirements applicable to using external supervisors. Inherent in the approach is what we refer to as 'supervisee initiated supportive supervision' whose characteristics include:

- The supervisees (ie, individual health worker or group or health facility) and where necessary, the supervisee's line manager, have the responsibility to identify supportive supervision needs using a number of tools and approaches internal to the health facility and together address the needs of the supervisee.

- In situations where the technical expertise is not internally available a request should be sent to the 'next level' for supportive supervision. The next level analyses the request and plans with the supervisee to provide supervision. In this way, external supervisors would have prior knowledge of the identified need to guide their planning, including the constitution of teams.

Positive experiences of the internal supportive supervision approach have been reported in Tanzania and Malawi, although challenges were highlighted as well. For example, time constraints associated with the dual role, where supervisors have to supervise lower level facilities and undertake direct supervision within their departments. ${ }^{28}$ The success of this approach must be 
anchored on a strong system for monitoring, data and information management at the health facility level. Bailey et al contend that supportive supervision as a standalone intervention, even with the most willing and motivated supervisees and supervisors, depends on systems that not only support their efforts but also enable them to influence processes that have a direct impact on their daily work. ${ }^{1}$ Both supervisees and supervisors should be trained to appropriately take on their roles in aspects such as individual and joint problem identification, processes for prioritisation and how and when to seek external support. Scholars argue that any modification in supportive supervision demands a significant paradigm shift, which supervisors and supervisees may not always find acceptable. ${ }^{11}$ There will be need to explore the feasibility of this approach on a small scale in some LICs.

\section{CONCLUSION}

The quality of health services is a core component of UHC. To this end, the inadequate human resources for health and other system-wide challenges in majority of LIC, accentuate the need for supportive supervision. The limitation in the current knowledge on what constitutes effective supervision and the imperative to understand how the different approaches influence performance in different social and cultural contexts needs to be addressed in order to realise the full benefits of the intervention. Thus, promoting a common understanding of the concept, a methodological shift that builds capacity at the lower levels of service delivery for internal supportive supervision especially in health facilities, is beneficial to reduce the systemic and logistical challenges that hinder implementation. Routine external supervisor paradigm and its accompanying funding and logistics requirements is not sustainable in many LICs. The quality of supportive supervision as opposed to frequency; human interactions built on trust, confidentiality and empathy and emphasis on task assistance are crucial.

Contributors GSA and JNO contributed to the conceptualisation of the study and led the drafting of the manuscript. All authors reviewed and approved the final manuscript and contributed to the review of literature.

Funding This study was funded by Who African Region.

Competing interests None declared.

Patient consent for publication Not required.

Provenance and peer review Not commissioned; externally peer reviewed.

Data sharing statement № additional data are available.

Open access This is an open access article distributed in accordance with the Creative Commons Attribution Non Commercial (CC BY-NC 4.0) license, which permits others to distribute, remix, adapt, build upon this work non-commercially, and license their derivative works on different terms, provided the original work is properly cited, appropriate credit is given, any changes made indicated, and the use is non-commercial. See: http://creativecommons.org/licenses/by-nc/4.0

\section{REFERENCES}

1. Bailey C, Blake C, Schriver M, et al. A systematic review of supportive supervision as a strategy to improve primary healthcare services in Sub-Saharan Africa. Int $J$ Gynaecol Obstet 2016;132:117-25.

2. Hill Z, Dumbaugh M, Benton L, et al. Supervising community health workers in low-income countries--a review of impact and implementation issues. Glob Health Action 2014;7:24085.

3. Thakral S. The historical context of modern concept of supervision. Journal of Emerging Trends in Educational Research and Policy Studies 2015;6:79-88.

4. Jones A. Clinical supervision: what do we know and what do we need to know? A review and commentary. J Nurs Manag 2006;14:577-85.

5. Martin P, Copley J, Tyack Z. Twelve tips for effective clinical supervision based on a narrative literature review and expert opinion. Med Teach 2014;36:201-7.

6. Deshpande A, Levy J, Hastings MB. Gender transformative supportive supervision: a theoretical framework. In: Management sciences for Health Leadership, Management and Government project. Washington DC, 2015.

7. Vasan A, Mabey DC, Chaudhri S, et al. Support and performance improvement for primary health care workers in low- and middleincome countries: a scoping review of intervention design and methods. Health Policy Plan 2017;32:437-52.

8. Willcox ML, Peersman W, Daou P, et al. Human resources for primary health care in sub-Saharan Africa: progress or stagnation? Hum Resour Health 2015;13:76.

9. Purity M, Eilish M, Ogenna U, et al. The impact of supportive supervision on the implementation of HRM processes: a mixedmethods study in Tanzania. Health Syst Policy Res 2017;04:47.

10. Manongi RN, Marchant TC, Bygbjerg IC. Improving motivation among primary health care workers in Tanzania: a health worker perspective. Hum Resour Health 2006;4:6.

11. Clements CJ, Streefland PH, Malau C. Supervision in primary health care - can it be carried out effectively in developing countries? Curr Drug Saf 2007;2:19-23.

12. Curtis P. Supervision in clinical midwifery practice. In: Butterworth T, Faugier J, eds. Clinical Supervision and Mentorship in Nursing. Boston, MA, 1992.

13. Kilminster S, Cottrell D, Grant J, et al. AMEE guide No. 27: effective educational and clinical supervision. Med Teach 2007;29:2-19.

14. Marquez L, Kean L, 2002. Making supervision supportive and sustainable: new approaches to old problems. Available from: https://usaidassist.org/sites/assist/files/maqno4final.pdf [Accessed 30 Aug 2018].

15. Garrison K, Caiola N, Sullivan R. Supervising health care services: Improving the performance of people. Washington DC: JHPIEGO, 2004.

16. Milne D. An empirical definition of clinical supervision. Br J Clin Psychol 2007;46(Pt 4):437-47.

17. Marecho EW. Factors influencing the role of quality assurance and standards officers in primary school curriculum implementation in Kitui County. University of Nairobi 2012.

18. Bernard JM, Goodyear RK, Bernard JM. Fundamentals of clinical supervision. London UK, 1992.

19. Care Quality Commission, 2013. Supporting information and guidance: supporting effective clinical supervision. Available from: http://www.cqc.org.uk/sites/default/files/documents/20130625800734-v1-00-supporting-information-effective-clinical-supervisionfor-publication.pdf [Accessed Aug 2018].

20. Marshall A, Fehringer J. Supportive supervision in monitoring and evaluation with community based health staff in HIV programs: a case study from Haiti. In: evaluation M, 2013.

21. Abiddin NZ. Exploring cinical supervision to facilitate the creative process of supervision. $J$ Int Soc Res 2008; 1 .

22. Schriver M, Cubaka VK, Itangishaka S, et al. Perceptions on evaluative and formative functions of external supervision of Rwandan primary healthcare facilities: a qualitative study. PLoS One 2018;13:e0189844

23. Milne $\mathrm{D}$, Aylott $\mathrm{H}$, Fitzpatrick $\mathrm{H}$, et al. How does clinical supervision work? Using a "best evidence synthesis" approach to construct a basic model of supervision. Clin Superv 2008;27:170-90.

24. Department of Health South Africa. Primary health care supervision mannual: a guide to primary health care facility supervision. Pretoria South Africa 2009.

25. Ministry of Health Ethiopia. Guidelines for supportive supervision in the health sector. Addis Abbaba Ethiopia: Ministry of Health Ethiopia, 2008.

26. Ministry of health Uganda. National supervision guidelines. Kampala Uganda: $\mathrm{MoH}, 2018$.

27. Guidelines Health Services. Guidelines for supportive supervision in the health sector. Accra Ghana: Services GH, 2017. 
28. Bradley S, Kamwendo F, Masanja H, et al. District health managers' perceptions of supervision in Malawi and Tanzania. Hum Resour Health 2013;11:43.

29. Glenton C, Colvin CJ, Carlsen B. Barriers and facilitators to the implementation of lay health worker programmes to improve access to maternal and child health: qualitative evidence synthesis. Cochrane Database Syst Rev 2013;10:CD010414.

30. Mor Barak ME, Travis DJ, Pyun H, et al. The impact of supervision on worker outcomes: a meta-analysis. Soc Serv Rev 2009;83:3-32.

31. Ameha A, Karim AM, Erbo A, et al. Effectiveness of supportive supervision on the consistency of integrated community cases management skills of the health extension workers in 113 districts of Ethiopia. Ethiop Med J 2014;52(Suppl 3):65-71.

32. Kisakye AN, Muhumuza Kananura R, Ekirapa-Kiracho E, et al. Effect of support supervision on maternal and newborn health services and practices in Rural Eastern Uganda. Glob Health Action 2017;10(sup4):1345496.

33. Henry R, Nantongo L, Wagner AK, et al. Competency in supportive supervision: a study of public sector medicines management supervisors in Uganda. J Pharm Policy Pract 2017;10:33.

34. Laínez YB, Wittcoff A, Mohamud Al, et al. Insights from community case management data in six sub-Saharan African countries. Am J Trop Med Hyg 2012:87(5 Suppl):144-50.

35. Rahman AE, lqbal A, Hoque DM, et al. Managing neonatal and early childhood syndromic sepsis in sub-district hospitals in resource poor settings: improvement in quality of care through introduction of a package of interventions in rural Bangladesh. PLoS One 2017;12:e0170267.

36. Madede T, Sidat M, McAuliffe E, et al. The impact of a supportive supervision intervention on health workers in Niassa, Mozambique: a cluster-controlled trial. Hum Resour Health 2017; 15:58.

37. Bosch-Capblanch X, Liaqat S, Garner P. Managerial supervision to improve primary health care in low- and middle-income countries. Cochrane Database Syst Rev 2011;9:CD006413.

38. Mor Barak ME, Travis DJ, Pyun H, et al. The impact of supervision on worker outcomes: a meta-analysis. Social Service Review 2009;83:3-32.

39. Hernández AR, Hurtig AK, Dahlblom K, et al. More than a checklist: a realist evaluation of supervision of mid-level health workers in rural Guatemala. BMC Health Serv Res 2014;14:112.
40. Panda B, Pati S, Nallala S, et al. How supportive supervision influences immunization session site practices: a quasi-experimental study in Odisha, India. Global Health Action 2015;8:25772.

41. Ministry of Health Swaziland. Supportive supervision mannual of community health workers in community-based health including HIV and Aids Services. Mbabane Swaziland: $\mathrm{MoH}, 2009$.

42. Lesotho Ministry of Health. Supportive supervision system for district health managemnet teams: a quide to primary health care supervision. Maseru Lesotho, 2010.

43. Roberton $\mathrm{T}$, Applegate J, Lefevre AE, et al. Initial experiences and innovations in supervising community health workers for maternal, newborn, and child health in Morogoro region, Tanzania. Hum Resour Health 2015;13:19.

44. Beddoe L. External supervision in social work: power, space, risk, and the search for safety $2011 ; 65: 197-213$

45. Onuka O, Madukwe O, Chukwueme N, et al. Use of smartphone for supportive supervision in Nigeria. iBusiness 2015;07:75-80.

46. George A, Tetui M, Pariyo GW, et al. Maternal and newborn health implementation research: programme outcomes, pathways of change and partnerships for equitable health systems in Uganda. Glob Health Action 2017;10(sup4):1359924.

47. Jacobs D, Dikgale F, Maartens T. Evaluation of primary health care supervision services in Mpumalanga Province. Bethesda, MD: USAID ASSIST Project, 2014.

48. Ludwick T, Turyakira E, Kyomuhangi T, et al. Supportive supervision and constructive relationships with healthcare workers support CHW performance: use of a qualitative framework to evaluate CHW programming in Uganda. Hum Resour Health 2018:16:11.

49. Leslie HH, Gage A, Nsona H, et al. Training and supervision did not meaningfully improve quality of care for pregnant women or sick children in sub-Saharan Africa. Health Aff 2016;35:1716-24.

50. Nkomazana O, Mash R, Wojczewski S, et al. How to create more supportive supervision for primary healthcare: lessons from Ngamiland district of Botswana: co-operative inquiry group. Glob Health Action 2016;9:31263.

51. Pakistan initiative for Mothers and Newborns (PAIMAN). Assessment of District Health Supervisory System. PAIMAN, 2006. 